\title{
DEVELOPING A WEB-BASED PPGIS, AS AN ENVIRONMENTAL REPORTING SERVICE
}

\author{
N. Ranjbar Nooshery ${ }^{a}$, M. Taleai ${ }^{b, *}$, R. Kazemi $^{c}$, K. Ebadi $^{d}$ \\ ${ }^{a}$ Master of civil engineering with major of GIS, K.N.Toosi University of Technology, Tehran, Iran - neda.geomatics@gmail.com \\ ${ }^{\mathrm{b}}$ Faculty of Geodesy and Geomatics Engineering, K.N.Toosi University of Technology, Tehran, Iran - taleai@kntu.ac.ir \\ ${ }^{\mathrm{c}}$ Graduate survey engineering, Survey College, National Cartographic Center, Tehran, Iran. \\ d PhD candidate in Communication Sciences, Islamic Azad University of Tabriz, Iran - kebadi56@yahoo.com
}

\author{
Commission IV, WG IV/4
}

KEY WORDS: PPGIS, SOLAP, Bottom-Up urban planning, Environmental reporting service, Web-GIS.

\begin{abstract}
:
Today municipalities are searching for new tools to empower locals for changing the future of their own areas by increasing their participation in different levels of urban planning. These tools should involve the community in planning process using participatory approaches instead of long traditional top-down planning models and help municipalities to obtain proper insight about major problems of urban neighborhoods from the residents' point of view. In this matter, public participation GIS (PPGIS) which enables citizens to record and following up their feeling and spatial knowledge regarding problems of the city in the form of maps have been introduced. In this research, a tool entitled CAER (Collecting \& Analyzing of Environmental Reports) is developed. In the first step, a software framework based on Web-GIS tool, called EPGIS (Environmental Participatory GIS) has been designed to support public participation in reporting urban environmental problems and to facilitate data flow between citizens and municipality. A web-based cartography tool was employed for geo-visualization and dissemination of map-based reports. In the second step of CAER, a subsystem is developed based on SOLAP (Spatial On-Line Analytical Processing), as a data mining tools to elicit the local knowledge facilitating bottom-up urban planning practices and to help urban managers to find hidden relations among the recorded reports. This system is implemented in a case study area in Boston, Massachusetts and its usability was evaluated. The CAER should be considered as bottom-up planning tools to collect people's problems and views about their neighborhood and transmits them to the city officials. It also helps urban planners to find solutions for better management from citizen's viewpoint and gives them this chance to develop good plans to the neighborhoods that should be satisfied the citizens.
\end{abstract}

\section{INTRODUCTION AND BACKGROUND}

These days, most of the municipalities search for ways to increase public participation unlike the past decades in which the urban planners have considered the public goals and rules down but they have developed their own decision without taking any advice from the resident side (Pissourios, 2014; Taleai et al., 2014). In fact, this is a change in the planning approach from traditional top-down to bottom-up models (Mansourian et al., 2011).

In bottom-up model, plans are developed at the lowest levels and are then passed on to the higher level. After that, they get to the senior management to be approved. The role of planners is mostly mediating among stakeholders and the focus of planning is on the process rather than outcome (Mohammadi, 2010). By using this application, municipalities get greater depth to the cities projects because more citizens are considered in the decision-making about their living place (Taleai et al, 2014). The term of public participation emerges here and the basic idea to use it is that people could control all decisions which effect on their lives.
By the late 1990s, public participation in planning was done through a meeting in which just a few people could participate due to the limitation in time and space. Public participation means citizens engagement in government's decision-making and sociologists believe people who are related to a public subject won't accept it unless they have been consulted about it (Paez, et al., 2003). According to Smith (1983), public participation is the process to "allow those affected by a decision to have an input into that decision. Scientists believe in many situations public participation is the only supplement for urban planning experts' knowledge to achieve the proper solutions as well as making correct decisions (Ball, 2002).

Traditional methods of public participation like methods which were held by city officials for entering citizens in the process of decision making would have brought a deal atmosphere because people had to discuss their opinions face to face and meetings which held in specific space and time is restricted to the number of people who could participate (Metla, 2008).

Arnstein has introduced a so-called participation ladder considering the degree of authority and citizens' powers. His ladder has divided different form of participation into 8 rungs. (Arnestein, 1996). The lower rungs represent low opportunities 
to participate, whereas, by moving up to the upper rungs, the citizens' power and authorities will be increased (Table 1).

Since 2002, Kingston et al. have developed e-ladder based on Widemann and Femers (1993) ladder which begins by online services and ends by online decision support systems. Kingston e-ladder shows different levels of participation based on interaction levels. It has one direction interactions in the first rungs and just gives or gets some information to/from participants but in higher levels, a 2-direction interaction has been provided.

\begin{tabular}{|c|c|c|c|c|}
\hline \multicolumn{2}{|c|}{ Arnestein's ladder } & Widemann and femer's & \multicolumn{2}{|c|}{ Kingston's e-ladder } \\
\hline Citizen Control & \multirow{3}{*}{ Citizen Power } & $\begin{array}{l}\text { Public participation in final } \\
\text { decision }\end{array}$ & $\begin{array}{l}\text { On-line decision } \\
\text { making }\end{array}$ & \multirow{5}{*}{$\begin{array}{l}\text { Two- Way } \\
\text { communication }\end{array}$} \\
\hline Delegated power & & $\begin{array}{l}\text { Public participation in } \\
\text { assessing risks and }\end{array}$ & Online PPGIS & \\
\hline Partnership & & recommending solutions & $\begin{array}{l}\text { Online Comments } \\
\text { on application }\end{array}$ & \\
\hline Placation & \multirow{3}{*}{ Tokenism } & \multirow{2}{*}{$\begin{array}{l}\text { Public participation in } \\
\text { defining interests, actors } \\
\text { and determining agenda }\end{array}$} & $\begin{array}{c}\text { Online service } \\
\text { delivery }\end{array}$ & \\
\hline Consultation & & & $\begin{array}{l}\text { On-line discussion } \\
\text { forums }\end{array}$ & \\
\hline Informing & & Public right to object & \multicolumn{2}{|c|}{ Communications barrier } \\
\hline Therapy & \multirow{2}{*}{$\begin{array}{c}\text { Non- } \\
\text { Participation }\end{array}$} & Informing the public & $\begin{array}{l}\text { Online Opinion } \\
\text { surveys }\end{array}$ & \multirow{2}{*}{$\begin{array}{l}\text { One- Way } \\
\text { communication }\end{array}$} \\
\hline Manipulation & & Public right to know & Basic Web Site & \\
\hline
\end{tabular}

Table 1. Different ladder of participation (Metla, 2008)

A new form of public participation has modelled in term of PPGIS $^{1}$ and web-based PPGIS (Ramadan, 2005; Bugs et al., 2010; Ganapati, 2011). PPGIS means applying geographical information system to enter the people into decision-making process (Jankowsky, 2009) and to facilitate the public participation in the planning process (Handsen and Prosperi, 2005). PPGIS enables citizens to tag their reports on a map and stores these geo-referenced reports in a spatial database. This way not only helps municipalities to find the exact location of reports more easily but also inserts automatically geo-referenced data in a spatial data warehouse and gives this chance to managers to execute different spatial analysis. Utilizing geovisualization tools are able managers to find hidden relations between stored reports.

Today there are different participation tools which make the citizen enable to join in planning and express their comments or problems 24 hours a day and 7 days a week and this capability can be considered as a requirement for new urban life. One of these services is Environmental On-Call Service (EOC) which enables citizens to report their un-emergency environmental problems via telephone, text-phone, text-messaging, email, online forums, Websites or mobile apps (Kingstone, 2007). These services are implemented in different cities of the world. For instance, in USA and Canada, they named 311 services $^{2}$. Seeclickfix ${ }^{3}$, enables the locale people to report non-emergency neighbourhood problems related to local governments. Users are able to add comments, videos or pictures. It currently covers more than 25000 towns and 8000 neighbourhoods both in the United States and abroad (techpersident.com/blogentry/seeclickfix-now-covering-25000-town-8000-

neighborhoods). According to statistics published by these services center, a large number of urban problems are reported daily and according to statics released by the 311 New York center, the number of recorded reports in different city districts was 161450 in October 2015 (www.nyc.gov/html/ops/1147/html/1147-report.html).
Entering data in a data warehouse enables managers to apply capabilities of analytical systems which are known as 'Business Intelligent' solutions (Almedia, 1999). By examining various BI solutions, data mining and OLAP could be suitable to analyze these reports. OLAP can be the best option due to its functional system in visualization, multi-dimensional presentation and data collection in micro levels as well as present them in macro levels (Rivest et al., 2005). Since one of the key elements of the environmental report is spatial, then applying Spatial OLAP (SOLAP), which combines GIS systems with OLAP, can help managers to display data on the map to compare different phenomenon and combine maps with statistical tables and graphs to obtain better information to handle spatial data (Thariqa, 2015).

There are many systems which have been designed earlier in the field of Web-GIS and SOLAP. Kingstone et al. (2000) developed virtual slaithwaith in a village in the north of England. This system enables rural residents to navigate on the map and tag their comment on it to enter them into decisionmaking process (Kingston, et al., 2000). Tang and Colemann developed $\mathrm{GeoDF}^{4}$ that combines web-based map interface with capabilities of online discussion forums for facilitating public participation in planning. People have been able to express their comments via messages or annotations on the map. Also, it was possible for everyone to comment on the existing discussion or start a new one (Tang, 2006). Mansourian et al. (2011) have proposed a framework, called Web-based participatory urban planning (WPUP), adjusted to a participatory urban planning approach. It offers a Web-based spatial forum to demonstrate how the proposed system can not only help citizens to share their idea regarding urban plans, but also help planners to implement applicable bottom-up and public participation decision-making theory in the urban planning process (Mansourian et al., 2011). Kingston developed a web-based map interface with the ability of geo-reference storing of reports and query for descriptive information to improve the environmental services (Kingston, 2007). Scotch and Permanto used SOLAP to develop SOVAT ${ }^{5}$, as a tool to visualize data to support decision making in community health assessment (Scotch and Permanto, 2005).

According to these issues, in this research, we propose CAER (Collecting \& Analyzing of Environmental Reports). It has two different parts for collecting and exploring citizens' reports. In fact, by reviewing existing systems and considering the needs of the environmental services, a web-GIS tool has been designed which empower the local people to have a flowing connection with municipalities via presenting information about recorded reports and facilitating expressing comments. In the second part, SOLAP has been utilized to help managers to discover the relations between reports and find the existing shortcomings. In fact, The CAER can be considered as a tool which can help to bottom-up planning through collecting people's problems and views about their neighborhood and transmits them to the city officials. It also helps them to find solutions for better management from citizen's viewpoint and gives them this chance to develop good plans to the neighborhoods. 


\section{SOLAP}

OLAP technology has developed based on multi-dimensional databases and its main concepts are dimensions, members, measures, facts and data cubes (Thomsen, 2002). Dimensions are the subjects in which the users are interested (Such as "Time", "Urban divisions" and "subject of reports"). The examples in dimensions are called members. For instance, the months in a year are the members of Time dimension. Measures are considered as numeric attributes measured in different dimensions. Each measure is subordinated to the dimensions for which context may be made. Each possible dimensions combination determining the measured value introduces a fact. For example, "The report's number with the street cleaning subject, in a specific municipality, districts in the first quarter (the first 3 months) in 2012", is a fact. These concepts are shown in Figure 1.

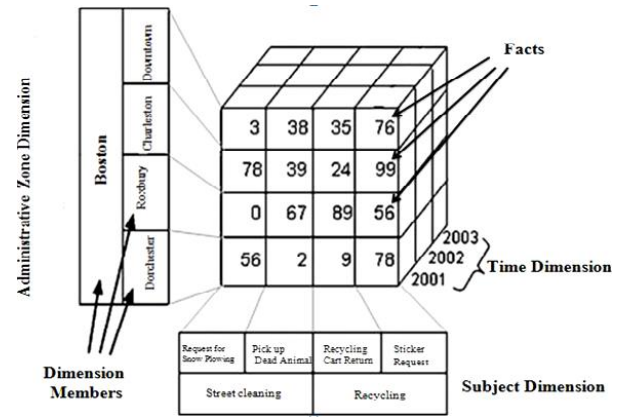

Figure 1. One example of data cube (Rivest et al., 2005)

Ordinary three components are involved in OLAP architecture: multidimensional database, OLAP server and OLAP client (Codreanu, 2011). An OLAP client can use a multidimensional database through the OLAP server. A multidimensional model allows the user to see data in different levels, from different aspects and level of details. There are multiple operators in OLAP which provide these capabilities. Some of these operators are drill-up (It transforms more detailed measures to less detailed ones and is done when an upward movement occurs in a cube), drill-down (It acts unlike the previous operator. In a hierarchy, it moves from more general levels to a more detailed level), Pivot (It rotates the cube to provide another data exhibition) and Slice (It makes selection in one cube dimension and produces a sub-cube).

Bédard has first introduced the idea of spatial OLAP in 1995 to support spatial dimensions. By integrating GIS and OLAP a new solution has been designed and called SOLAP (Rivest et al., 2005). The SOLAP system architecture consists of a spatialtemporal database with multidimensional structure, a spatial OLAP server and an OLAP client (Body et al., 2003). Spatial OLAP server utilizes multidimensional spatial-temporal database and calculates measure values in possible compositions of dimensional members. The SOLAP client helps the users to explore multidimensional spatial databases in different information levels and shows the results to them by applying maps, tables and diagrams (Bédard et al., 2005). Three different types of spatial dimensions are supported by an SOLAP system: non-geometric spatial dimensions, geometric spatial dimensions and mixed spatial dimensions. The first type only supports the places names like Boston, Dorchester and etc. The geometric spatial dimensions involve vector-based geometric shapes (Like polygons to show the neighbourhoods boundary) for all dimensions' members and at all levels. They are spatially referenced to let their dimensional members to be observed and queried cartographically. Mixed spatial dimensions use a mixture of both non-geometric and geometric spatial dimensions.

\section{ARCHITECTURE OF THE PROPOSED PPGIS}

Figure 2 illustrates the architecture of the developed PPGIS system for environmental services.

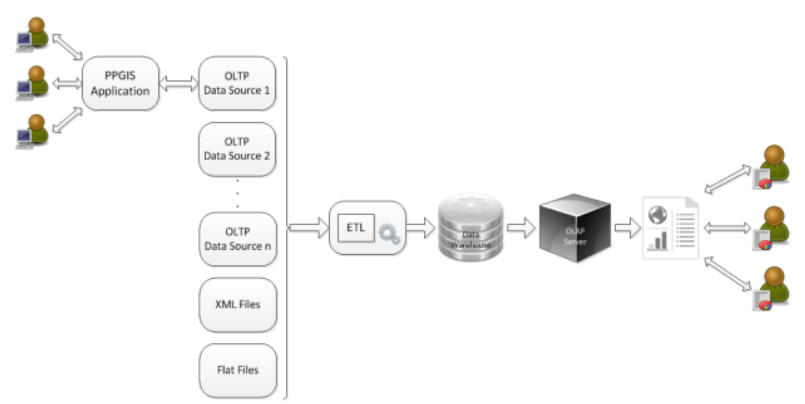

Figure 2. Architecture of the developed system for environmental services

The proposed system has been designed as dual-subsystem architecture to meet our needs. The first is a PPGIS which enables citizens to tag their reports on a map, upload videos and the place pictures, see the recorded reports distributions and others views, also it enters the reports to a spatial database so that provides the opportunity to the managers to execute spatial analysis. PPGIS segment includes three layers: presentation layer, logic layer and data layer. These layers are typical of client/server architecture (Figure 3). According to studies, Google map has been selected among the web-based development platforms as a development platform of the system on the client side. It provides powerful programming interface with easy to use applications and adequate documentation. The logic layer contains Web server, Application server, Google map server and environmental service server. Data layer manages available data in the database and calls required data for the data layer. Also, each recorded report or updates must be saved in this layer.

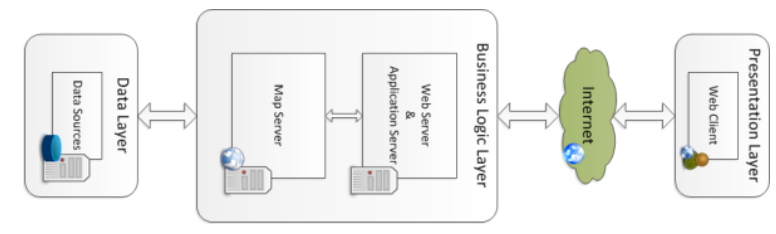

Figure 3. Architecture of the developed PPGIS system

Presentation layer has been designed to present users the information, achieve their input, create input and display it on the user's system. By applying this layer, Users can see the location map and find desired location on the map, record new reports in the target location, update the recorded reports and also see the recorded reports distribution. Presentation layer contains user interface and web client technologies. According to the studies, Google map has been selected among the webbased development platforms as a system development platform on the client side. It provides powerful programming interface with easy using applications and adequate documentation. 
Logic layer contains Web server, Application server, Google map server and PPGIS server. Web server is http server which handles the communication between the client and the server. Server receives users request via http protocol, translates it through application server and sends it to Google map server and PPGIS server. Google map server supplies maps while PPGIS server sends recorded reports and information to the presentation layer. Also new recorded reports are sent to the data layer.

The major purpose is to explore the recorded reports and discover the relations between them as well as communications between these reports and their occurrence time and place. The SOLAP system includes four layers (Figure 4). In Data layer, data are extracted from sources, cleaned, transformed and loaded into the data warehouse, commonly is called ETL $^{6}$ process which stands for extraction, transformation, and loading. ETL process is utilized to enter recorded reports to a spatial data warehouse, categorizes and presents them in different levels and dimensions. This layer contains all the required data for spatial analysis and to transfer them to a spatial data warehouse.

An essential function in the SOLAP system is to execute the different queries on the reports and present the results. To get this, firstly the reports should be entered to a spatial data warehouse. Then managers can apply SOLAP tools to execute different queries and see the results on maps or in different tables at different time or space levels.

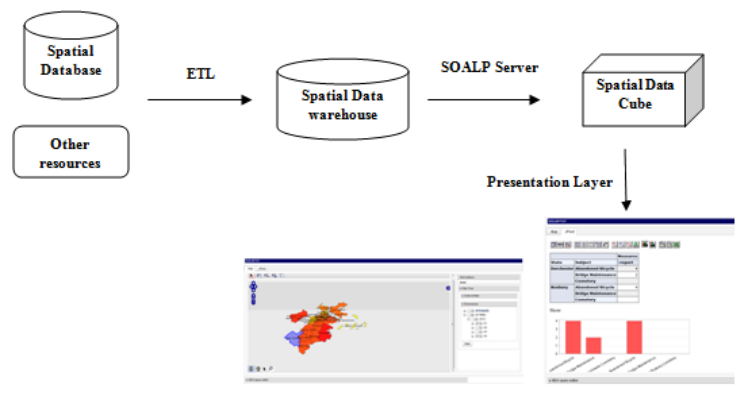

Figure 4. Architecture of the developed SOLAP system

\section{IMPLEMENTATION AND RESULTS}

The proposed system is implemented for Boston to show its capabilities. As previously mentioned, the proposed system has two subsystems. In PPGIS subsystem, presentation layer involves Google maps API which retrievals maps and satellite images from Google server. Furthermore, this layer contains web forms that enable users to record their reports. Web client technologies such as dynamic HTML, CSS, JavaScript and AJAX is used for developing the component of this layer. Also for communicating with ER servers and building dynamic web pages PHP programming language has been applied. PostgreSQL database and pgsql language are used for data management and spatially storing of reports.

When a user enters in the website, the system is asked to select the neighbourhood of the report. With doing this the map of next page will be navigated to the selected neighbourhood. This ability helps uses to find their target location more easily.
As is shown in Figure 5 there are some markers on the map on the main page which specify the location of recorded reports. A user can open register form by double clicking on the desired location. After registering the report, a tracking code will be given to the user. But if there is a marker in the desired location with the same subject, the user can open updating form by clicking on the marker and update the before registered report. In this case, it won't be resaved in the main database and will be sent to another one but a counter in the main database counts the number of updating. This number is saved to specify the repeatability of a report as a measure of its importance.

Also, the system has a good cartographic capability to show all of the reports with different markers to give the users a view of the distribution of various reports in neighbourhoods. This capability is shown in Figure 5.

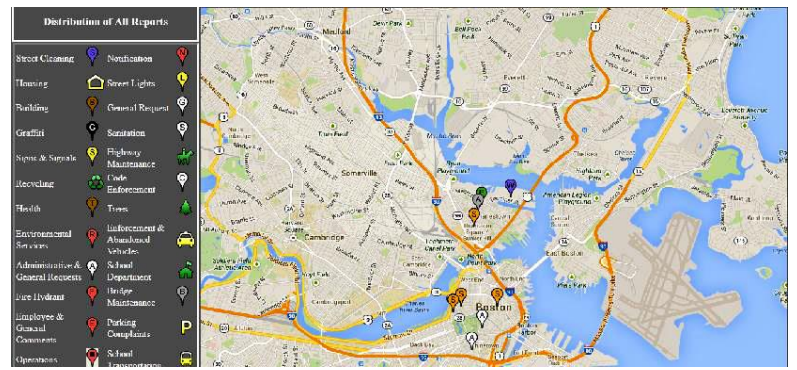

Figure 5. Cartographic capability of the system to represent recorded reports

In SOLAP part of the system, dimensions are:

- Urban problems: It is non-spatial dimension and has twolevel hierarchies including subject and sub-subject,

- Reported events: It is spatial dimension and has one level hierarchy,

- Urban divisions: It is spatial dimension and has two-level hierarchies including the city and the neighbourhoods,

- Time: It is a non-spatial dimension and has three level hierarchies includes the year, quarter and month.

The applied measure is the number of the report and required data including:

- A file contains reports subject and sub-subject which may happen in the city (there is an excel file which contains all subjects and sub-subjects).

- The obtained database from first system part that contains users' geo-referenced reports about their neighbourhoods (this is junction points of system two parts).

- Shape files of city divisions (Shape files of Boston's neighbourhood and boundary).

- A File contains time intervals (There is a CSV file).

After gathering the mentioned data, which can have different formats, Spatial ETL is performed using GeoKettle ${ }^{7}$ (Figure 6). Spatial ETL provides the data processing functionality of traditional Extract, Transform, Load (ETL) software, but with a primary focus on the ability to manage spatial data (which may 
also be called GIS, geographic, or map data). A spatial ETL system translates data directly from one format to another, or via an intermediate format. This tools are user-created geoprocessing tools that can transform data between different data models and different file formats. Then data are entered into the spatial data warehouse. Also by storing the spatial ETL process, it could be updated every day. The PostgreSQL and PostGIS are applied as the data warehouse.

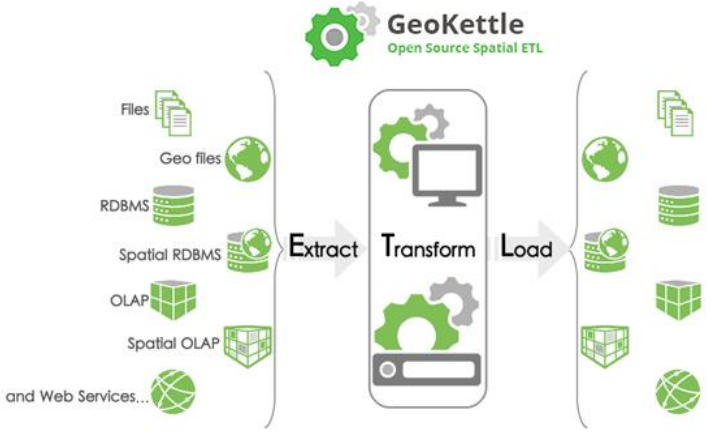

Figure 6. GeoKettle as a metadata-driven spatial ETL tool (http://www.spatialytics.org/projects/geokettle/)

After implementing the spatial data warehouse, data cube logical model is designed. Regarding the attributes of different schemas, the logical model is designed by using snowflake schema. This schema is designed by using Workbench ${ }^{8}$. The Workbench outcome is an XML file that contains the built schema. By using this file, spatial OLAP server communicates with data in the spatial data warehouse and data are loaded in the data cube. Also, the analysis and interactive fast exploring in different dimensional levels are made possible with the SOLAP server help. In this system, Geomondrian ${ }^{9}$ is used which is an open source server for SOLAP. In the next step, a web-based user interface is designed to allow urban managers and planners to use this spatial analysis system. They can visualize measurement values in different dimensional levels and give maps, tables and charts. Also, it enables them to run several queries on different levels and dimensions of the data cube. To create this user, GeoAnalysis Tools 0.6 is used.

Apache tomcat 6.1 is used to present the designed user interface. This interface has two tabs: Map and JPivot ${ }^{10}$. Map tab presents non-spatial dimensions on its left side as a drop-down list and shows spatial dimensions on the maps. Users can navigate the map by zooming or panning. Also, there are drill-down and drill-up options on the map which enables users to move up or down in the spatial dimension. Furthermore, there is a select tool on the map that allows the user to select desired part on the map to get information. The user can select the non-spatial dimension desired levels from the drop-down list and execute different queries on the data cube. Figure 7 presents a view of SOLAP system and Map tab. It is shown the result of "comparing the number of "general request" and "highway maintenance" subjects in "Mission Hill" and "Downtown" neighbourhoods at "May 2012".

${ }^{8}$ A common product of Pentaho and Spatialytics as a schema designing tool

${ }^{9}$ Spacialytics SOLAP server and a spatial version of Mondrian that is OLAP server tool

${ }^{10}$ SOLAP engine
On the other hand, non-spatial dimensions in designed data cube are presented in JPivot tab with charts and tables. This developed SOLAP system tab is presented in Figure 8 which shows the last query result.

Regarding the system abilities in providing reports at different dimensions and levels, urban planners can run various queries and interpolate system outcomes with their knowledge about the city. They can see weekly, monthly or yearly reports about the neighbourhoods. Also by visualizing system capabilities, they do not need a complex algorithm to extract hotspot places for specific problems because they can be identified easily.

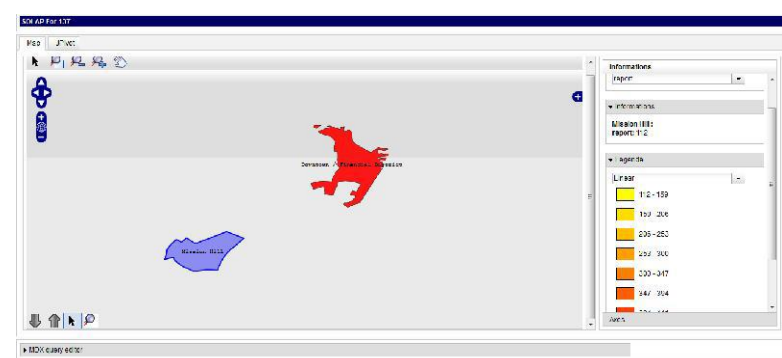

Figure 7. Map tab of the developed system

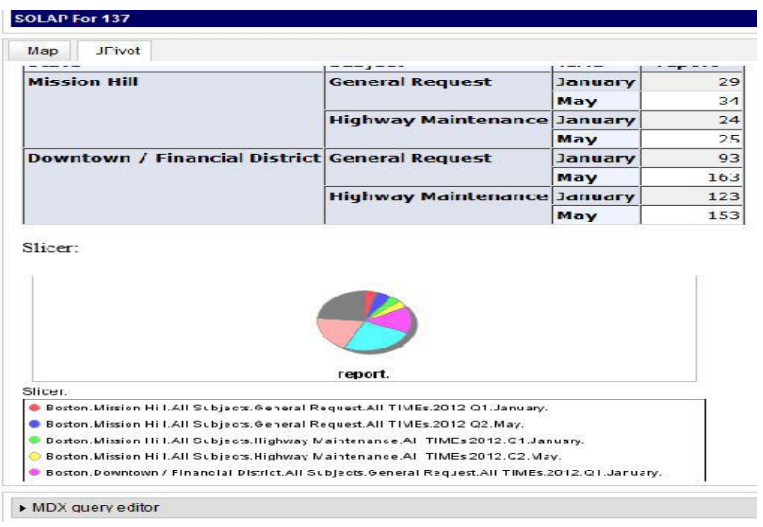

Figure 8. JPivot tab of the developed system

\section{DISCUSSION AND CONCLUSIONS}

In this research, A PPGIS is designed for environmental services to collect peoples' reports. This system enables citizens to tag their reports on the map and update the existing reports. Also, it has the cartographical capability in presenting information to the citizens and structure to prevent data redundancy. It can courage people to get more participation by knowing this fact that their reports are important for the city officials.

In SOLAP subsystem, the recorded reports in the spatial database are transformed to the data warehouse and this process would be repeated every day. As mentioned earlier, there are good analyses which can be useful but SOLAP would be the best option because of its unique abilities in gathering data in low levels, presenting them in macro levels as well as indicating data in the form of charts, tables and reports. This analysis is applied to help managers to discover the hidden relations between reports.

In some aspects, there is a query to show how the managers can run different queries on the recorded reports. They can design different questions and run them on the data warehouse and 
interpret the results with their prior knowledge about the neighbourhoods. Therefore, this system can help city officials to develop the best plans to omit the root problems on the way of neighbourhoods' improvement. In fact, it is away forward bottom-up planning.

Despite all the advantages of the proposed system, implementing it in developing countries like Iran has many difficulties. For example, at first this system was designed to improve 137 services in Iran but because of inaccessibility to needed data, finally it is tested in Boston.

Furthermore, although participatory GIS has become a more widespread and accepted in developmental practices, there is evidence that local Elite and state agencies attempt to control the practice. Such projects in developing countries are often externally driven and geared towards data management instead of community empowerment which can be provoking and needs more control (Rambaldy et al., 2005). Additionally, developed SOLAP system has many capabilities but non-spatial dimensions are not connected in two different tabs. This is because of the presentation layer weakness. There are not many tools for SOLAP systems presentation layers and available tools have many defects. This can be considered as a weakness of the system or to a field to get more research.

\section{ACKNOWLEDGMENTS}

The authors would like to say thanks to Municipality of Boston, which kindly let us have data of this city.

\section{REFERENCES}

Almeida, S.M., Ishikawa, M., Reinschmidt, J., Roeber, T., 1999. Getting Started with Data warehouse and Business Intelligence, IBM -International Technical Support Organization, San Jose.

Arnstein S-R., 1969. A Ladder of Citizen Participation. Journal of the American Planning Association, 35 (4), pp. 216-224.

Ball J., 2002. Towards a methodology for mapping regions for sustainability using PPGIS, Progress in Planning, 58, pp. 81140.

Bédard Y., Rivest, S., Proulx, M-J., 2005. Spatial Online Analytical Processing (SOLAP): Concepts, Architectures, and Solutions from a Geomatics Engineering Perspective. A chapter in Data Warehouses and OLAP: Concepts, Architectures and Solutions, EDA Group, United states.

Body, M., Miquel, M., Bédard, Y., Tchounikine, A., 2003. Handling Evolutions in Multidimensional Structures. Proceedings 19th International Conference on Data Engineering, Bangalore, India IEEE: 581-591.

Codreanu, D.E., 2011. Modelling Financial-Accounting Decisions by Means of OLAP Tools. Database Systems Journal, 2(1), pp. 23-32.

Ganapati, S., 2011. Uses of public participation geographic information systems application in e-government. Public Administration Review, 71(3), pp. 425-434.

Jankowsky, P., 2009. Toward participatory geographic information system for community-based environmental decision making. Journal of Environmental Management, 90(6), pp. 1966-1971.
Kingston, R., 2007. Public Participation in local policy decision making: the role of web-based mapping. The Cartographic Journal, 44(2), pp. 138-144.

Kingston, R., Carver, S., Evans, A., Turton I., 2000. Web-based Public Participation geographic information systems: an aid to local environmental decision-making. Computers. Environment and urban systems, 24, pp. 109-125.

Mansourian, A., M. Taleai, and A. Fasihi, 2011. A web-based spatial decision support system to enhance public participation in urban planning processes. Journal of Spatial Science, 56(2), pp. 269-282.

Metla, J-A., 2008. Participation technologies: a framework for the development of an online interactive GIS application. M.Sc Thesis, Iowa State University, Ames, United States.

Mohammadi, H., 2010. Citizen Participation in Urban Planning and Management: The case of Iran, Shiraz City, Saadi Community, PhD Thesis, Kassel University Press $\mathrm{GmbH}$, Kassel.

Paez, D, Bishop, I-D, Williamson, I-P., 2003. Spatial \& temporal representation of environmental policy outcomes using geo-computation: a case study in Victoria Australia. In: ESRI International users conference, San Diego, United States, 7-11 July 2003.

Pissourios, 2014. Top-down and bottom-up urban and regional planning: towards a framework for the use of planning standards. European Spatial Research and Policy, 21(1), pp. 83-99.

Rambaldi, G., et al., 2005. Participatory Spatial Information Management and Communication in Developing Countries, Mapping for Change International Conference, Nairobi, Kenya, 7-10 Septemer.

Rivest, S., Bédard, Y., Proulx, M-J., Nadeau, M., Hubert, F., Pastor, J., 2005. SOLAP technology: Merging business intelligence with geospatial technology for interactive spatiotemporal exploration and analysis of data. ISPRS Journal of Photogrammetry \& Remote sensing, 60(1), pp. 17-33.

Scotch, M., B., Parmanto, 2005. Development of SOVAT: A numerical-spatial decision support system for community health assessment research. International journal of medical informatics, pp.771-784.

Smith, L.G. 1983. Impact assessment and sustainable resource management. Longman, Harlow, UK.

Taleai, M., R., Sliuzas, J., Flacke, 2014. An integrated framework to evaluate the equity of urban public facilities using spatial multi-criteria analysis. Cities, 40 (2014), pp. 56-69.

Tang, T., 2006. Design and implementation of a GIS-enabled On-line discussion forum for participatory planning. M.Sc Thesis, Department of Geodesy and Geomatics Engineering Technical Report, University of New Brunswick, Canada.

Thariqa, P. and I., Sukaesih, 2015. Monitoring Spatial online analytical processing for hotspots distribution based on socioeconomic factors in Riau Province Indonesia, Sitanggang. Procedia Environmental Sciences. 24 (2015), pp. 277-284.

Thomsen E., 2002. OLAP Solutions: Building Multidimensional Information Systems, 2nd edition. Wiley. New York, United States. 
Wiedemann, I., S., Femers, 1993. Public participation in waste management decision making: analysis and management of conflicts. Journal of Hazardous Materials, 33, pp. 355-368. 